\title{
The Relationship between Alexithymia and Attachment Styles among University Students
}

\author{
Lama M. Qaisy ${ }^{1, *} \&$ Muna A. Abu Darwish ${ }^{2}$ \\ ${ }^{1}$ Department of Educational Psychology, Faculty of Educational Sciences, Tafila Technical University, Jordan \\ ${ }^{2}$ Department of Special Education, Faculty of Educational Sciences, Al-Hussein Bin Talal University, Jordan \\ *Corresponding author: Department of Educational Psychology, Faculty of Educational Sciences, Tafila Technical \\ University, Jordan. E-mail: lamaqaisy@yahoo.com
}

Received: December 1, 2017

Accepted: August 31, 2018

Online Published: October 12, 2018

doi:10.5430/wje.v8n5p104

URL: https://doi.org/10.5430/wje.v8n5p104

\begin{abstract}
The study aimed to investigate the relationship between Alexithymia (Alex) and attachment styles, gender, family size, parent's level of education among a randomly selected sample of (392)undergraduate students (136 male, 256 female), at Al-Hussein Bin Talal University. To achieve the objectives of this study, the twenty-item Toronto Alexithymia Scale (TAS-20), which was standardized by Dawoud (2016) and Yarmouk Attachment Scale developed by Abu Ghazal and Jaradat (2009) were applied, after verifying their validity and reliability. The results of the study revealed a significant negative correlations between Alex and secure attachment, while the correlations between Alex and avoidant attachment, and anxious-ambivalent attachment styles were positively significant. Also, there was significant positive correlation between Alex with gender and family size. Finally; no significant correlations were found between Alex with parent's education.
\end{abstract}

Keywords: Alexithymia, attachment styles, family size

\section{Introduction}

The awareness of consciousness is an evidence for the emotional, social and vocational efficiency of the individuals, and the emotional expression is considered to be one of the human behavior forms which could be used to evaluate his personality and his ability to communicate with others and attract their attention and form a sympathetic relationship with them. Alex was derived from the Greek root of Alexi (Lack of words) in 1973 by Sifneosit refers to an incapability to express emotions; which means the difficulties in understanding emotions. It now refers to a set of interrelated difficulties: identifying and distinguishing between feelings and the bodily sensations of emotional arousal; difficulty describing feelings. (Tahir, Ghayas, \& Tahir, 2012, Alilu, Abdolmohamadi, Zade, Hamidi, Basmenj, 2014, Gilbert, McEwan, Catarino, Baiao, Palmeira, 2014), Moriguchi, Decety, Ohnishi, Maeda, Nemoto, Matsuda, and Komaki (2006) indicated that Alex is the lack of knowledge of expressing the emotional experiences. It is associated with specific mental disorders. In addition to that, it externally oriented thinking to focus on external rather than internal events and experiences. Leweke, Leichsenring, Kruse, \& Hermes (2011). Bermond, Vorst, and Moormann (2006) concluded that Alex covers many aspects of the lack of empathy. Because empathy depends on vicarious sharing of the feelings and thoughts of others, this common representational network between the self and others in conjunction with self-other awareness provides the basic mechanism for empathy. From this perspective, Alex may be associated with impairment in empathy, show poor performance in identifying the emotional values of facial expressions, (Moriguchi, Decety, Ohnishi, Maeda, Nemoto, Matsuda, and Komaki, 2006) characterized Alex individuals by: unable to identify, understand, or describe their own emotions and some of them are unable to talk about their feelings.

Alex is an acquired trait because the family play a great role in teaching their members the values of love, empathy, self-confidence and emotions expression, it is considered to be an evidence for the efficiency of emotional social and vocational feeling of any individual, these feelings make the individuals unable to communicate with others, attract their attention and build a Sympathetic relationship with them (Dawoud, 2016). This was also ensured by studying Alex among twins; which indicated that it is an acquired trait and not an inherited one (Abu Ghazal and Jaradat, 
2009). Gunsch (2010) realized that the expression of emotions can be learned from the surrounding environment; family is considered the main source for teaching their members the values of love, empathy, honesty, care, trust, and loyalty, parents usually protect their sons and daughters from having problems, especially by implementing an effective communication system that provide the family members with chances of how to talk, listen, and feel with each others.

Alex frequently accompanied with many developmental and psychological disorders, such as; autism spectrum disorder, panic disorder, somatoform disorders and substance abuse, physical and mental health problems such as coronary spasm, (Lemche, Klann-Delius, Koch, and Joraschky 2004), depression, anxiety, obsessive-compulsive behaviors and thoughts, and personality disorders (Paull, 2013), sleep disorders and eating disorders Ahadi, Azizi Nejad, Narimani and Berahmand, 2014).

Attachment is a strong emotional bond between two people characterized by emotional exchange and the desire to sustain proximity, and usually lead to the child's feeling of happiness and security when he is close to the caregiver, and the feeling of tension and discomfort when separated from him (Hadad, 2001), attachment is considered as the emotional bond between the mother and the growing child that develops from birth, but the effect is not limited to childhood rather extends to all periods of life, even old age (Abu Ghazal and Jaradat, 2009). Attachment style determines how people communicate with each other and how to manage the threatening situations and what strategies are employed) Abadi, Abdolmohamadi, Kheiradin, and Roodsari, 2015).

Attachments have three types: secure, avoidant, and anxious-ambivalent. Individuals with a secure attachment style feel comfortable with intimacy and emotional attachment, ensure that the responses of others and their viewpoints about love are positive and true (Pakdaman \& Khanjani, 2011). Avoidant attachment style is combined with cold, exclusion, and without support care and thereby increases the feeling of self-reliance. Anxious -ambivalent attachment style is associated with the unstable and non-uniform care caused by anxiety and anger (Ahadi, Azizi Nejad, Narimani, and Berahmand, 2008). The study of Lemchea, Klann-Delius, Koch, and Joraschky (2004) showed that insecurely attached children were expected to have difficulties in symbolizing bodily processes, it was expected that insecure and disorganized groups would have less linguistic tools for emotion regulation; since certain relations of attachment security with cognitive capacities had been demonstrated, it was assumed that differences in cognition vocabulary would become apparent.

Several studies had been conducted on the subject of Alex such as the study of Dawoud (2016) that aimed to examine the relationship between Alex and parental styles, socio-economic status, family size, and gender among the undergraduate sample from the college of educational sciences, at Jordan University. The results of the study revealed a significant negative correlation between Alex and parental styles. Also, there was significant negative correlation between Alex and family income, and no significant correlations were found between Alex with family size, father's and mother's education, and there are no statistically significant differences in Alex were found due to gender, family size, father's education and mother's education.

The study of Hamad (2016) applied Alex scale on a sample that consisted of (107) male and (93) female from Baghdad University, the results indicated that the level of Alex in the sample was mid, and female students had a higher level of Alex than males.

The study by Besharat and Salimian Rizi (2014) examined the mediating role of self-regulation on the relationship between secure, avoidant, and ambivalent attachment styles with Alex in a sample of undergraduate students consisted of 546 volunteers. The results showed that the secure attachment style showed a significant negative association with Alex, while avoidant and ambivalent attachment styles showed significant positive associations with Alex. Analysis of the data revealed that the relationship between attachment styles and Alex was mediated by self-regulation. Secure attachment style as the main effective factor in the development of impressive emotion regulation skills provides good identification, expression and better exchange of emotions in social and emotional interactions by reinforcement of self-regulation.

The study of Paull (2013) aimed to explore whether a group of care-leavers differed from a group of similarly aged individuals who grew up with their birth families with respect to Alex, attachment security, and psychological distress. The sample consisted of 2 groups: care-leavers $(n=43)$ and comparison group $(n=43)$ which consisted of young adult students who attended a further education college in the same geographical area. The results showed that the care-leaver group reported significantly higher scores on the Alex measure. Significant positive correlations were found between attachment, Alex, and psychological distress. 
Shaheen (2013) conducted a study aimed at detecting differences in life satisfaction and Alex. The study sample consisted of (250) students. The results showed statistically significant differences in life satisfaction on the scale of Alex, there were also differences between males and females on the scale of Alex in favor of males.

Larsenab, Strienab, Eisingac, and Rutger (2005) also conducted a study on varicose and sex differences. The study sample consisted of 343 females and 70 males aged 18-60 years. The results showed that females had higher levels of Alexithymia than males.

In a study that aimed to investigate the relationship between adult attachment behavior and Alex among a sample consisted of 301 University students of Bologna/Italy, Montebarocci, Codispoti, Baldaro, and Rossi (2004) concluded that there was a moderate positive correlation between Alex and attachment style.

Barbera, Christensen, and Barchard (2004) conducted a study aimed at identifying the relationship between family size and Alex in a sample of 102 participants. The Toronto Alexithymia scale was used. The results showed that people living in large families had a high level of Alex compared to people living in small families.

\section{Statement of the Problem}

Alex is one of the traits accompanied by internal and external behavioral problems. This study aimed to study the relationship between Alex and attachment styles because Alex affects the psychological growth of the students, their ability to adapt to the university life, and affects their friendly relations with others.

This study will precisely answer the following questions:-

1 - What is the degree of Alex among university students?

2- What is the relationship between Alex and attachment styles that exist among university students?

3- What is the relationship between Alex and gender, family size, and parent's education?

\section{Study Importance}

Alex is considered to be one of the important topics in psychology and counseling, this study will highlight the characteristics of students regarding Alex and attachment and their relationship with some variables that may affect students mental health, in addition to that the researchers found a shortage in Arabic literature regarding Alex and its relation with attachment.

\section{Methodology}

\subsection{Population}

The study population included (4866) students in7 faculties (2234) male, female (2632).

\subsection{Sample}

The study sample consisted of (392) students (136 male, 256 female), at Al-Hussein Bin Talal university (ABT) during the summer semester (2016/2017), who were randomly chosen.

\subsection{Instrument}

\subsubsection{Alex Scale}

The researchers adopted the Jordanian version of Toronto Alexithymia Scale which was standardized for Jordanian environment by Dawoud (2016). The scale consists of 20 items, and 3 domains: difficulty identifying feelings ( 7 items), difficulty describing feelings (5 items), and externally oriented thinking (8 items). The participants were asked to respond to the scale using 5 points Likert scale.

\subsubsection{Attachment Scale}

The researchers used Yarmouk Attachment Scale which was developed by Abu Ghazal and Jaradat (2009). The scale consisted of 20 items and 3 domains: secure attachment style (6 items), avoidant attachment style ( 7 items), and anxious-ambivalent attachment style ( 7 items). The participants were asked to respond to the scale using 6 points Likert scale.

\subsection{Validity}

To validate the instrument 2 methods were used, the first one is expert judgments, the researchers rechecked their validity by sending them to 8 experts in counseling and psychology, to check their face validity, and they reported 
that the 2 instruments were valid to be used for the study purposes. The 2 nd method is the internal correlation between items of the 2 scales with their domains and with the total score on each scale table (1) and (2) represent the findings.

Table 1. Correlations between Items with Their Domains and with the Total Score

\begin{tabular}{ccccccccc}
\hline & $\begin{array}{c}\text { Difficulty } \\
\text { Identifying } \\
\text { Feelings }\end{array}$ & $\begin{array}{c}\text { Alexithymi } \\
\text { a Total }\end{array}$ & $\begin{array}{c}\text { Difficulty } \\
\text { Describing } \\
\text { Items }\end{array}$ & $\begin{array}{c}\text { Alexithymia } \\
\text { Total }\end{array}$ & & $\begin{array}{c}\text { Externally } \\
\text { Oriented } \\
\text { Iteminking }\end{array}$ & $\begin{array}{c}\text { Alexithymia } \\
\text { Total }\end{array}$ \\
\hline 1 & $.607^{* *}$ & $.472^{* *}$ & 8 & $.439^{* *}$ & $.470^{* *}$ & 13 & $.474^{* *}$ & $.331^{* *}$ \\
2 & $.653^{* *}$ & $.507^{* *}$ & 9 & $.451^{* *}$ & $.194^{* *}$ & 14 & $.400^{* *}$ & $.354^{* *}$ \\
3 & $.618^{* *}$ & $.515^{* *}$ & 10 & $.501^{* *}$ & $.368^{* *}$ & 15 & $-.440^{* *}$ & $-.323^{* *}$ \\
4 & $.691^{* *}$ & $.562^{* *}$ & 11 & $.525^{* *}$ & $.470^{* *}$ & 16 & $.470^{* *}$ & $.276^{* *}$ \\
5 & $.729^{* *}$ & $.601^{* *}$ & 12 & $.476^{* *}$ & $.371^{* *}$ & 17 & $.441^{* *}$ & $.182^{* *}$ \\
6 & $.700^{* *}$ & $.517^{* *}$ & & & & 18 & $.496^{* *}$ & $.241^{* *}$ \\
7 & $.641^{* *}$ & $.567^{* *}$ & & & & 19 & $-.495^{* *}$ & $-.335^{* *}$ \\
& & & & & & 20 & $.562^{* *}$ & $.368^{* *}$ \\
\multicolumn{2}{l}{ Domain total } & $.804^{* *}$ & Domain total & $.678^{* *}$ & Domain total & $.639^{* *}$ \\
\hline
\end{tabular}

The results indicated positive significance correlation $(\alpha=0.05)$ between the items of difficulty identifying feelings, difficulty describing feelings, and externally oriented thinking domains and the total score of Alex, except for item (15), which indicated negative significant correlation with externally oriented thinking domains and with the total score of Alex.

Table 2. Correlations between the Items of Attachment with Their Domains

\begin{tabular}{cccccc}
\hline $\begin{array}{c}\text { Secure Attachment } \\
\text { Style Items }\end{array}$ & Correlations & $\begin{array}{c}\text { Avoidant } \\
\text { Attachment Style } \\
\text { Items }\end{array}$ & Correlations & $\begin{array}{c}\text { Anxious } \\
- \text { Ambivalent } \\
\text { Attachment } \\
\text { Style Items }\end{array}$ & Correlations \\
\hline 4 & $.446^{* *}$ & 2 & $-.463^{* *}$ & 1 & $-.536^{* *}$ \\
7 & $.549^{* *}$ & 5 & $-.603^{* *}$ & 3 & $-.690^{* *}$ \\
10 & $.561^{* *}$ & 8 & $-.510^{* *}$ & 6 & $-.624^{* *}$ \\
11 & $.571^{* *}$ & 12 & $-.509^{* *}$ & 9 & $-.561^{* *}$ \\
14 & $.571^{* *}$ & 15 & $-.555^{* *}$ & 13 & $-.444^{* *}$ \\
19 & $.552^{* *}$ & 18 & $-.459^{* *}$ & 16 & $-.552^{* *}$ \\
& & 20 & $-.560^{* *}$ & 17 & $-.589^{* *}$ \\
\hline
\end{tabular}

Table (2) shows that the correlations between the items of secure attachment style with the domain were positively significant $(\alpha=0.05)$, while the items of avoidant attachment style domain and anxious-ambivalent attachment style domain were negatively significant $(\alpha=0.05)$.

\subsection{Reliability}

The reliability of the study tools was checked, using test-retest and internal consistency (Cronbach $\alpha$ equation); pilot sample consisted of 40 students was used to check reliability, using test re-test method. The tools were applied 2 times; the duration time between the two applications was 10 days. Table (3) represents the findings for reliability concerning the two methods. 
Table 3. Reliability of the Scales

\begin{tabular}{|c|c|c|c|}
\hline Scales & Domains & Test-retest & $\begin{array}{l}\text { internal consistency } \\
(\operatorname{cronbach} \alpha)\end{array}$ \\
\hline \multirow{4}{*}{ Alex } & $\begin{array}{c}\text { Difficulty Identifying } \\
\text { Feelings }\end{array}$ & 0.85 & 0.81 \\
\hline & $\begin{array}{c}\text { Difficulty Describing } \\
\text { Feelings }\end{array}$ & 0.79 & 0.71 \\
\hline & $\begin{array}{c}\text { Externally Oriented } \\
\text { Thinking }\end{array}$ & 0.88 & 0.82 \\
\hline & Total & 0.90 & 0.88 \\
\hline \multirow{4}{*}{ Attachment } & Secure Attachment & 0.81 & 0.77 \\
\hline & Avoidant Attachment & 0.79 & 0.75 \\
\hline & $\begin{array}{c}\text { Anxious - Ambivalent } \\
\text { Attachment }\end{array}$ & 0.84 & 0.79 \\
\hline & Total & 0.89 & 0.81 \\
\hline
\end{tabular}

\section{Results and Discussion}

Question 1: What is the degree of Alex among university students?

To answer this question the participants were distributed into 3 levels of Alex according to their grades on Alex scale: low level (20-47), mid-level (48-75), and high level (76-100). Table (4) represents the findings.

Table 4. The Distribution of Participants According to Their Alex Grades

\begin{tabular}{ccc}
\hline Level & Students Number & $\%$ \\
\hline High & 43 & $11 \%$ \\
Mid & 321 & $82.1 \%$ \\
Low & 28 & $6.9 \%$ \\
\hline
\end{tabular}

As shown in table (4) $82.1 \%$ of the students had mid-level of Alex, 11\% had a high level of Alex, while $6.9 \%$ had a low level of Alex. This result is similar to the findings of (Dawoud, 2016, Montebarocci, Codispoti, Baldaro, and Rossi, 2004). Through comparing these values with the results in other communities, it is concluded that the level of Alex was high, for example, it was (18-25\%) in British, Canadian, and Finland communities (Mason, Tyson, Jones, and Potts, 2005, Dawoud, 2016, Shaheen, 2013). This could be explained depending on the fact that western communities focus more interest on emotional aspects of the personality and the freedom of expressing their emotions and feelings more than Arab communities, which inhibits feeling expression by males; also it inhibits females to express their emotions because of the traditions.

Question 2: What is the relationship between Alex and attachment styles that exist among university students?

To answer question 2, person correlation coefficient was used, table (5) represents the findings.

Table 5. Correlation Coefficients between Alex Domains and Attachment Domains

\begin{tabular}{lcccc}
\hline Attachment Style & & $\begin{array}{c}\text { Difficulty } \\
\text { Identifying Feelings }\end{array}$ & $\begin{array}{c}\text { Difficulty } \\
\text { Describing Feelings }\end{array}$ & $\begin{array}{c}\text { Externally } \\
\text { Oriented Thinking }\end{array}$ \\
\hline Secure Attachment Style & Pearson Correlation & $-.083-$ & $-.023-$ & $-.062-$ \\
& Sig. (2-tailed) & .100 & .657 & .220 \\
Anxious -Ambivalent & $\mathrm{N}$ & 392 & 392 & 392 \\
Attachment Style & Pearson Correlation & $.261^{*}$ & $.195^{*}$ & $.031^{*}$ \\
& Sig. (2-tailed) & .000 & .000 & .540 \\
Avoidant Attachment Style & $\mathrm{N}$ & .192 & 392 & 392 \\
Pearson Correlation & .031 & $.099^{*}$ & $.004^{*}$ \\
\multicolumn{2}{c}{ Sig. (2-tailed) } \\
$\mathrm{N}$ & 392 & .050 & .942 \\
& & 392 & 392 \\
\hline
\end{tabular}

*. Correlation is significant at the 0.05 level (2-tailed). 
The components of attachment styles, avoidant and ambivalent attachment styles have a positive significant relationship $(\alpha=0.05)$ with all Alex domains, while secure attachment style has a negative significant relationship with all Alex domains.

Research on adolescents and adults shows that individual with secure attachment style reports lower levels of negative emotions and establishes strong relationships with others who can provide them with support when emotionally distressed. However, individuals with insecure attachment style in comparison with secure ones, experience lower levels of positive emotions and show the inability to manage stress, anxiety, depression and other negative emotions (Morley \& Moran, 2011). The study of Abu Ghazal and Jaradat (2009) showed that children with secure attachment during childhood will have good relations during the adult stage.

Question 3: What is the relationship between Alex and gender, family size, and parent's education?

To answer question 3, person correlation coefficient was used, table (6) represents the findings.

Table 6. Person Correlations between Alex and Gender, Family Size, and Parent's Education

\begin{tabular}{lcccccc}
\hline & SUMALEX & Gender & $\begin{array}{c}\text { Family } \\
\text { size }\end{array}$ & $\begin{array}{c}\text { Father's } \\
\text { Education }\end{array}$ & $\begin{array}{c}\text { Mother's } \\
\text { Education }\end{array}$ \\
\hline SUMALEX & Pearson Correlation & 1 & $.195^{* *}$ & $.104^{*}$ & $-.079-$ & $-.052-$ \\
& Sig. (2-tailed) & & .000 & .039 & .116 & .302 \\
Gender & $\mathrm{N}$ & 392 & 392 & 392 & 392 & 392 \\
& Pearson Correlation & $.195^{* *}$ & 1 & .075 & $-.008-$ & $-.009-$ \\
& Sig. (2-tailed) & .000 & & .139 & .876 & .854 \\
Family size & $\mathrm{N}$ & 392 & 392 & 392 & 392 & 392 \\
& Pearson Correlation & $.104^{*}$ & .075 & 1 & $.101^{*}$ & .080 \\
& Sig. (2-tailed) & .039 & .139 & & .046 & .114 \\
Father's & $\mathrm{N}$ & 392 & 392 & 392 & 392 & 392 \\
Education & Pearson Correlation & $-.079-$ & $-.008-$ & $.101^{*}$ & 1 & $.766^{* *}$ \\
& Sig. (2-tailed) & .116 & .876 & .046 & & .000 \\
Mother's & $\mathrm{N}$ & 392 & 392 & 392 & 392 & 392 \\
Education & Pearson Correlation & $-.052-$ & $-.009-$ & .080 & $.766^{* *}$ & 1 \\
& Sig. (2-tailed) & .302 & .854 & .114 & .000 & \\
*. Correlation & N & Significant at the 0.05 level (2-tailed). & 392 & 392 & 392 & 392 \\
\hline
\end{tabular}

Table (6) shows that there is a positive significant correlation between Alex with gender in favor of females (mean of Alex for males $=59.8 \mathrm{~S} . \mathrm{D}=9.5$, mean of Alex for females=64.0 S.D=10.2). The high mean of Alex among females may be due to the conservative nature of Jordanian society which enables males to express their feelings than females. This result is similar to the findings of Hammad (2016), Larsenab, Strienab, Eisingac, and Rutger (2005), whereas it disagrees with the findings of Dawoud (2016), and Shaheen (2013). The results also indicated a positive significant correlation between Alex and family size in favor of large family size (more than 5 individuals) (mean for small families size (less than 5 individuals) $=61.2 \mathrm{~S} . \mathrm{D}=8$, mean for large families size $=63.1 \mathrm{~S} . \mathrm{D}=10.2$ ), the results agree with the findings of Barbera, Christensen, and Barchard (2004), and disagree with the findings of Dawoud (2016). This may be due to the increasing responsibilities of families with a larger size, where the focus is on providing everyday life requirements which lead to neglecting the psychological needs.

\section{Recommendations}

Based on the results of this study, the researchers suggest the following recommendations:

Conducting more studies using other variables associated with Alex such as marital satisfaction, personality pattern, depression, and social relationships, educating instructors about the concept of Alex and its importance in student relations and social adaptation with others, and developing counseling programs that contribute to the treatment of Alex among the students.

\section{Conclusion}

Emotions have a great role in buildings social relations, communication with others and socio-psychological 
adaptation, in addition to that attachment is considered to be a strong relationship that makes the person feels happy and safe among people whom they provide him with support and care. Hence, this study was conducted and came to the following Conclusion: Alex level was mid among most of the students (82.1\%), and was higher among females and large number families, according to that counselors at universities have to work on developing students' methods of expressing their emotions in civilized forms.

\section{References}

Abadi, F., Abdolmohamadi, K., Kheiradin, J., \& Roodsari, A. (2015). Prediction of Alexithymia on the Basis of Attachment Style and Early Maladaptive Schemas in University Students. Research papers, 1(3), 39-46.

Abu Ghazal, M., \& Jaradat, A. (2009). Adult Attachment Styles and their Relationship to Self-Esteem and Loneliness. Jordanian Journal of Educational Sciences, 5(1), 45-57.

Ahadi, B., Azizi Nejad, F., Narimani, F., \& Berahmand, A. (2008). Explanation of Obsessive-Compulsive Disorder in Terms of Attachment Styles and Defense Mechanisms (Persian). Journal of Behavioral Sciences, 2(4), 339-343.

Alilu, M., Abdolmohamadi, K., Zade, M., Hamidi, R., \& Basmenj, N. (2014). The Role of Defensive Mechanisms and Emotional Regulation in Alexithymia. Journal of Current Research in Science, 2(3), 395-400.

Barbera, K., Christensen, M., \& Barchard, K. (2004). Relating Family Size and Birth Order to Emotional Intelligence. Poster Presented At The 2004 Western Psychological Association Annual Convocation: Phoenix Arizona.

Bermond, B., Vorst, H., \& Moormann, P. (2006). Cognitive Neuropsychology of Alexithymia: Implications for personality Typology. Cognitive Neuropsychiatry, 11, 332-360. https://doi.org/10.1080/13546800500368607

Besharat, A., \& Salimian Rizi, M. (2014). The Relationship Between Attachment Styles and Alexithymia: Mediating Role of Self-Regulation. International Journal of Research Studies in Psychology, 3(4), 89-98. https://doi.org/10.5861/ijrsp.2014.839

Dawoud, N. (2016). The Relationship between Alexithymia and Parental Styles, Socioeconomic Status, Family Size, and Gender. Jordanian Journal of Educational Sciences, 12(4), 415-434.

Gilbert, P., McEwan, K., Catarino, F., Baiao, R., \& Palmeira, L. (2014). Fears of Happiness and Compassion in Relationship with Depression,Alexithymia, and Attachment Security in A Depressed Sample. Britsh Journal of Clinical Psychology, 53, 228 - 244. https://doi.org/10.1111/bjc.12037

Gunsch, J. (2010). What is Alexithymia? Retrieved from http://www.wisegeek.com/what-is-alexithymia.htm

Hadad, Y. (2001). Attachment Patterns and their Relationship to Interaction Social, and Psychological Adjustment of University Students. Educational Science Studies, 2, 479-456.

Hamad, N. (2016). Application Alexithymia Measure of University Students. Journal of Al-Ostath Especial Issue Number of the Fourth Scientific Conference. Bagdad University. http://dx.doi.org/10.1080/13546800500368607

Larsenab, J., Strienab, T., Eisingac, R., \& Rutger, E. (2005). Gender Differences in Association between Alexithymia and Emotional Eating in Obese Individuals. Journal of Psychosomatic Research, 60(3), 237-243. https://doi.org/10.1016/j.jpsychores.2005.07.006

Lemche, E., Klann-Delius, G., Koch, R., \& Joraschky, P. (2004). Mentalizing Language Development in a Longitudinal Attachment Sample: Implications for Alexithymia. Psychother Psychosom, 73(6), 366-374. https://doi.org/10.1159/000080390

Leweke F., Leichsenring F., Kruse J., \& Hermes S. (2011). Is Alexithymia Associated with Specific Mental Disorders. Psychopathology, 45, 8-22. https://doi.org/10.1159/000080390

Mason, O., Tyson, M., Jones, C., \& Potts, S. (2005). Alexithymia: Its Prevalence and Correlates in a British Undergraduate Sample. Psychology and Psychotherapy: Theory, Research and Practice, 78, 113-125. https://doi.org/10.1348/147608304X21374

Montebarocci, O., Codispoti, M., Baldaro, B., \& Rossi, N. (2004). Adult Attachment Style and Alexithymia. Personality and Individual Differences, 36, 499-507. https://doi.org/10.1016/S0191-8869(03)00110-7

Moriguchi, Y., Decety, J., Ohnishi, T., Maeda, M., Mori., T., Nemoto, K., Matsuda, H., \& Komaki, G. (2006). Empathy and Judging Other's Pain: An Fmri Study of Alexithymia. Cerebral Cortex, 17(9), 2223-2234. https://doi.org/10.1093/cercor/bhl130 
Morley, T. E., \& Moran, G. (2011). The Origins of Cognitive Vulnerability in Early Childhood: Mechanisms Linking Early Attachment to Later Depression Review Article. Clinical Psychology Review, 31, 1071-1082. http://dx.doi.org/10.1016/j.cpr.2011.06.006

Pakdaman, S., \& Khanjani, M. (2011). The Role of Perceived Parenting in the Relationship between Attachment Style and Collectivism in Students (Persian)]. Journal of Social Psychology Studies, 1(4), 81-103.

Paull, K. (2013). Alexithymia, Attachment and Psychological Wellbeing in Young Adults Leaving Care. Doctoral thesis, Cardiff University.

Shaheen, H. (2013). Alexithymia and Life Satisfaction among Sample of Students University. Journal of Education College in Banha, 96(1), 81-112.

Tahir, I., Ghayas, S., \& Tahir, W. (2012). Personality Traits and Family Size as the Predictors of Alexithymia among University Undergraduates. Journal of Behavioral Sciences, 22(3), 104-119. 